\title{
ANALISIS JALUR DAN BIAYA PEMASARAN JAMUR MERANG TANKOS DI PROVINSI LAMPUNG
}

\section{PATH ANALYSIS AND MARKETING COSTS OF STRAW MUSHROOMS OF TANKOS IN LAMPUNG PROVINCE}

\author{
Sri Astuti ${ }^{1 *}$ dan Sarono ${ }^{2}$ \\ ${ }^{1}$ Dosen pada Jurusan Ekonomi dan Bisnis Politeknik Negeri Lampung \\ ${ }^{2}$ Dosen pada Jurusan Teknologi Pertanian Politeknik Negeri Lampung \\ E-mail corresponding : astuti@polinela.ac.id
}

\begin{abstract}
ABSTRAK
Budidaya jamur merang dari tandan kosong kelapa sawit (tankos) di Provinsi Lampung berkembang cukup baik. Hal ini karena adanya permintaan pasar yang tinggi dan ketersediaan bahan baku yang melimpah dan murah, sehingga menjadikan usaha jamur merang dari tankos lebih kompetitif dibandingkan dengan jamur merang dari merang dan jerami padi. Tujuan penenilitan adalah analisis jalur-jalur pemasaran dan biaya yang dikeluarkan terkait pemasaran jamur merang dari tankos di Provinsi Lampung. Metode penelitian dilakukan melalui survey dan indeep interview, dengan responden pemilik usaha, karyawan, supplier, dan pedagang pertama, pedagang pengecer jamur merang tankos. Data yang diperoleh selanjutnya ditabelkan dan ditampilkan secara grafis serta dinarasikan agar mudah dipahami. Hasil penelitian menunjukkan bahwa (1) jalur pemasaran jamur merang dari tankos ada tiga yaitu jalur panjang (produsen - pedagang pertama - pedagang pengecer - konsumen); jalur sedang (produsen - pedagang pengecer - konsumen); dan jalur pendek (produsen - konsumen) dan (2) pelaku usaha jamur merang tankos yang paling untung adalah produsen jamur merang tankos, sedangkan yang paling beresiko tetapi potensi keuntungan tertinggi adalah pedagang pertama.
\end{abstract}

Kata Kunci : Jalur Pemasaran, Jamur Merang, Tankos

\begin{abstract}
Mushroom cultivation from empty fruit bunch (EFB) in Lampung Province is growing quite well. It could be happened because of the high market demand and the availability of abundant and cheap raw materials, so that the mushroom business from EFB is more competitive than mushroom from rice straw. The research objective is to analyze the marketing channels and costs associated with the marketing of EFB mushrooms in Lampung Province. Research methods were obtained through survey, in-depth interviews with business owners, employees, suppliers, and the first traders, retailers of tankos mushroom. The obtained data were tabulated and displayed graphically and narrated for easy understanding. The results showed that (1) there are three marketing channels for mushroom from tankos, namely the long route (producer - first trader - retailer - consumer); medium line (producer - retailer - consumer); and short paths (producer - consumer) and (2) the most profitable tankos business are the producers of tankos mushrooms, while the one of the most risk but the highest potential profit is the first trader
\end{abstract}

Keywords: marketing channels, straw mushroom, empty fruit bunch (EFB) 


\section{ANALISIS JALUR DAN BIAYA PEMASARAN JAMUR MERANG TANKOS DI PROVINSI \\ LAMPUNG}

Sri Astuti dan Sarono

\section{PENDAHULUAN}

Tandan kosong kelapa sawit (Tankos) merupakan suatu produk samping (by product) kelapa sawit yang jumlahnya cukup besar mencapai sekitar $23 \%$ dari total tandan buah segar, Prosentase tankos setara dengan produk utama kelapa sawit yaitu CPO (Saelor, et al., 2017). Jumlah yang besar ini harus dicarikan alternatif pemanfaaatannya agar tidak menjadi masalah lingkungan. Salah satu produk alternatif yang dapat dikembangkan adalah pemanfaatan tankos menjadi kompos (pupuk tanaman). Proses pengomposan tankos secara alami memerlukan waktu yang cukup lama, oleh karena itu dibantu dengan jamur pelapuk putih. Salah satu jamur pelapuk putih yang juga dapat menghasilkan pangan adalah adalah jamur merang.

Dewasa ini pemanfaatan tankos sebagai bahan untuk media tanam jamur merang sudah berkembang di Provinsi Lampung. Beberapa lokasi usaha jamur merang tankos yang berproduksi secara rutin antara lain di Raman Aji Lampung Timur, Metro Timur, dan Simbaringin Natar Lampung Selatan.

Hasil penelitian Bakce dkk. (2019), menyatakan bahwa banyak faktor penyebab kegagalan pengembangan usaha jamur merang berbahan baku TKKS antara lain skala usaha dan biaya pemasaran, skala usaha yang terlalu kecil tidak mencapai skala ekonomi. Bahkan dalam implementasi usaha jamur merang berbahan baku TKKS, Bakce dkk. (2019) melakukan pendampingan manajemen pemasaran produk. Oleh karena itu, perlu diteliti penyebab kegagalan usaha jamur merang berbahan TKKS di Provinsi Lampung. Tujuan penelitian adalah sebagai berikut :Analisis jalur-jalur pemasaran jamur merang tankos di Provinsi Lampung dan Analisis biaya pemasaran pelaku usaha jamur merang tankos dari Provinsi Lampung.

\section{METODE PENELITIAN}

Penelitian dilakukan dengan metode studi kasus dengan mengambil sampel jalur dan biaya pemasaran jamur merang tankos di Provinsi Lampung. Pengambilan sampel dilakukan dengan memawancara setiap jalur pemasaran 3 orang pelaku usaha kemudian hasilnya dirata-ratakan.

Penelitian aspek produksi jamur merang tankos dilaksanakan di tiga lokasi, yaitu Unit Usaha Jamur Merang Tankos Raman Aji, Kabupaten Lampung Timur; Unit Usaha Jamur Merang Tankos Metro Timur, Kota Metro; dan Unit Usaha Simbaringin, Natar, Kabupaten Lampung Selatan. Penelitian jalur dan biaya pemasaran dilakukan mulai dari unit usaha sampai pedagang pengecer baik di dalam Provinsi Lampung maupun di luar Provinsi Lampung, seperti pedagang 
pengecer jamur Bandar Lampung, Natar, Metro, Kotabumi, Palembang, Batam, dan Jakarta.

Cara pengambilan data dengan wawancara dilakukan melalui survey dan melihat proses produksi jamur merang secara langsung, indeep interview terhadap pemilik usaha, karyawan, supplier, dan pedagang pertama, pedagang pengecer jamur merang tankos. Pedagang pertama adalah pedagang yang langsung mengambil jamur dari produsen jamur, sedangkan pedagang kedua adalah pedagang yang mengambil jamur dari pedagang pertama.

Data yang diperoleh selanjutnya ditabelkan dan ditampilkan secara grafis serta dinarasikan agar mudah dipahami.

Data investasi yang diperlukan adalah jenis dan jumlah serta biaya barang yang diperlukan untuk membuat kumbung jamur, biaya tenaga kerja untuk membuat kumbung jamur, dan umur kumbung jamur. Data biaya operasional adalah jumlah dan harga bahan, biaya tenaga kerja dan biaya lain yang diperlukan (Sahadewa dkk., 2019).

\section{HASIL DAN PEMBAHASAN}

Sentra Produksi Jamur Merang Tankos

Hasil penelitian menunjukkan bahwa di Provinsi Lampung terdapat beberapa produsen jamur merang yang menggunakan tankos sebagai media tanamnya. Beberapa usaha di berbagai lokasi pernah dicoba, tetapi yang produksinya tidak kontinyu dan tidak lanjut. Tiga lokasi yang produksinya kontinyu dan tetap berproduksi sampai saat ini dapat dilihat pada Tabel 1.

Tabel 1. Unit Usaha Jamur Merang Bermedia Tanam Tankos di Lampung

\begin{tabular}{|c|c|c|c|c|}
\hline No. & Uraian & $\begin{array}{l}\text { Raman Aji, } \\
\text { Lampung Timur }\end{array}$ & $\begin{array}{l}\text { Natar, Lampung } \\
\text { Selatan }\end{array}$ & $\begin{array}{l}\text { Metro Timur, } \\
\text { Metro }\end{array}$ \\
\hline 1. & $\begin{array}{l}\text { Jumlah Pemilik Usaha } \\
\text { (Unit) }\end{array}$ & 4 & 1 & 1 \\
\hline 2. & Kontinyuitas Produksi & Kontinyu & Kontinyu & Kontinyu \\
\hline 3. & Jumlah Kumbung (unit) & $35-68$ & 12 & 4 \\
\hline 4. & $\begin{array}{l}\text { Ukuran Kumbung } \\
\text { Rata-rata }(\mathrm{m})\end{array}$ & $5 \times 6 \times 6$ & $5 \times 6 \times 6$ & $5 \times 6 \times 5$ \\
\hline 5. & Lokasi Pemasaran & $\begin{array}{l}\text { Sekitar pabrik, } \\
\text { Metro, Bandar } \\
\text { Jaya, Bandar } \\
\text { Lampung, Jakarta, } \\
\text { Palembang, Batam }\end{array}$ & $\begin{array}{l}\text { Sekitar pabrik, } \\
\text { Natar, dan } \\
\text { Bandar Lampung }\end{array}$ & $\begin{array}{l}\text { Sekitar Pabrik } \\
\text { dan Metro }\end{array}$ \\
\hline 6. & $\begin{array}{l}\text { Jumlah Produksi } \\
\text { (kg/hari) }\end{array}$ & $200-620$ & $50-150$ & $5-40$ \\
\hline 7. & $\begin{array}{l}\text { Produk Olahan selain } \\
\text { Jamur Segar }\end{array}$ & Tidak ada & Tidak ada & Tidak ada \\
\hline
\end{tabular}




\section{ANALISIS JALUR DAN BIAYA PEMASARAN JAMUR MERANG TANKOS DI PROVINSI \\ LAMPUNG}

Sri Astuti dan Sarono

Hasil penelitian Sarono dkk (2020), menunjukkan bahwa usaha jamur merang menggunakan media tanam tankos memerlukan keseriusan usaha tidak bisa sebagai usaha sampingan. Misalnya pemanenan hasil dilakukan pagi dan sore hari, kontrol suhu dan kelembaban $(\mathrm{RH})$ dilakukan setiap 6 jam, serta pemasaran hasil harus dilakukan segera setelah dipanen. Budidaya jamur merang bermedia tankos mempunyai potensi ekonomi yang menjanjikan. Hal ini karena media tanam yaitu tankos harganya cukup murah dan mudah didapat, permintaan yang masih tinggi, sarana penunjang mudah didapatkan.

\section{Jalur Pemasaran Jamur Merang}

\section{Tankos.}

Jalur pemasaran jamur merang tankos di Lampung dapat dilihat pada Gambar 1. Penentuan jalur pemasaran ditentukan oleh jumlah pelaku pemasaran (Fitriady MY., 2011).

Hasil penelitian jalur pemasaran jamur merang yang berasal dari sentra jamur merang Raman Aji Lampung Timur lebih luas dibandingkan dengan sentra jamur merang Natar, Lampung Selatan dan sentra jamur Metro. Sentra jamur merang Raman Aji Lampung Timur memasarkan produknya sampai luar Provinsi Lampung yaitu Jakarta, Palembang, dan Batam. Di samping itu juga memasarkan di dalam provinsi dan konsumen langsung di sekitar unit usaha. Sedangkan sentra jamur merang Natar dan sentra jamur Metro hanya memasarkan produknya di dalam Provinsi Lampung dan konsumen langsung di sekitar unit usaha.

Jalur pemasaran jamur merang tankos dapat dikelompokkan menjadi tiga jalur pemasaran, yaitu :
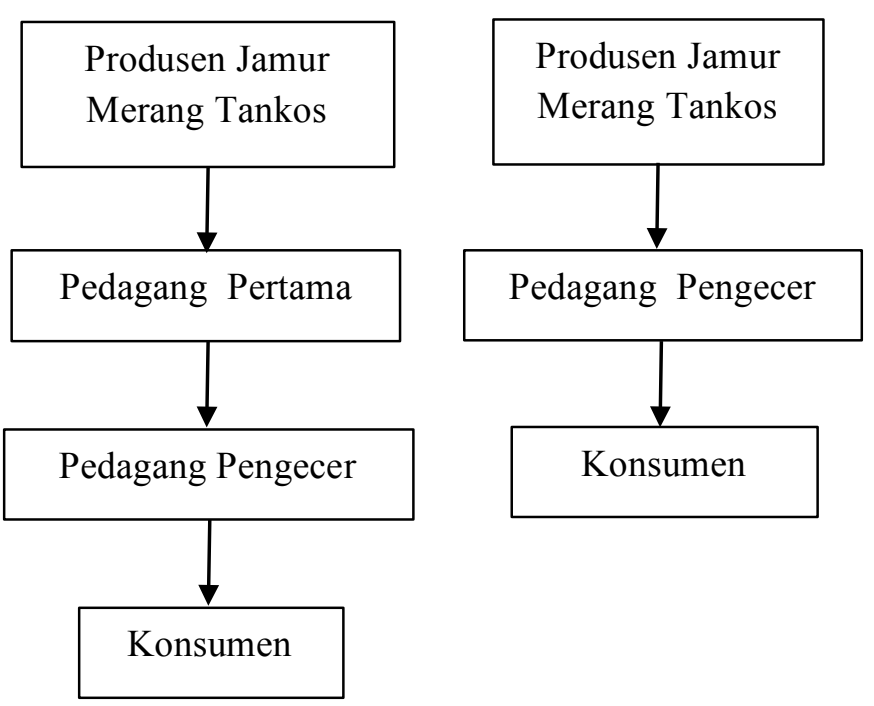

Produsen Jamur Merang Tankos
(a) Jalur Panjang
(b) Jalur Sedang
(c) Jalur Pendek

Gambar 1. Jalur Pemasaran Jamur Merang Tankos di Lampung 
a. Jalur Panjang atau jalur luar provinsi (Jakarta, Palembang, dan Batam)

b. Jalur Sedang atau dalam provinsi (Bandar Lampung, Natar, Metro, Bandar Jaya, dan Kotabumi)

c. Jalur Pendek atau sekitar unit usaha (langsung konsumen)

Hasil penelitian menunjukkan bahwa pemasaran jalur panjang atau jalur luar provinsi mampu mendokrak kuantitas pemasaran dibandingkan jalur pemasaran sedang dan pendek. Hal ini karena area pemasaran lebih luas dan lebih tahan terhadap perubahan harga (Fitriady, 2011). Hasil penelitian juga menunjukkan bahwa produsen jamur selain mengambil pemasaran jalur panjang, juga masih mengambil pemasaran jalur sedang dan pendek. Pemasaran yang lebih luas dan pangsa pasar yang lebih variatif ternyata mampu menopang kelangsungan usaha yang lebih baik (Burano dan Yuliza, 2020).

\section{Analisis Biaya Jalur Pemasaran Jamur}

\section{Merang Tankos}

(1) Penjual Pertama Jamur Merang Tankos

Penjual pertama jamur tankos adalah pedagang perantara yang mengambil jamur merang tankos dari produsen untuk disalurkan ke pedagang pengecer. Penjual pertama yang menjual jamur merang tankos dalam penelitian ini adalah sebagai berikut :

(a) Unit Usaha Raman Aji Lampung Timur menjual jamur merang tankos ke pedagang pengecer di luar Provinsi Lampung (Jakarta, Palembang, dan Batam), dalam Provinsi Lampung (Bandar Lampung, Metro, Bandar Jaya, Kota Bumi, dan kota-kota lain di Provinsi Lampung).

(b) Unit Usaha Metro menjual jamur merang tankos ke pedagang pengecer di dalam Provinsi Lampung (Metro dan Bandar Jaya).

(c) Unit Usaha Simbaringin Natar Lampung Selatan untuk dijual ke pedagang pengecer di dalam Provinsi Lampung (Bandar Lampung dan Natar).

Rekapitulasi analisis biaya jalur pemasaran jamur merang tankos di Provinsi Lampung dapat dilihat pada Tabel 2. Hasil penelitian menunjukkan biaya-biaya yang dikeluarkan oleh penjual pertama jika menjual ke pengecer di luar Provinsi Lampung adalah sebagai berikut:

(a) Tranportasi dan resiko dari Unit Usaha Raman Aji Lampung Timur ke lokasi pedadang pengecer Jakarta, Palembang, dan Batam adalah Rp. 8.000 sampai dengan Rp. $12.00 / \mathrm{kg}$ jamur merang. 


\section{ANALISIS JALUR DAN BIAYA PEMASARAN JAMUR MERANG TANKOS DI PROVINSI \\ LAMPUNG}

Sri Astuti dan Sarono

(b) Tranportasi dan resiko dari Unit Usaha Raman Aji Lampung Timur ke lokasi pedadang pengecer Bandar Lampung, Metro, Bandar Jaya, Kotabumi adalah Rp. 4.000 sampai dengan Rp. 5.00/kg jamur merang. (c) Tranportasi dan resiko dari Unit Usaha Metro ke lokasi pedadang pengecer Metro dan Bandar Jaya adalah Rp. 4.000 sampai dengan Rp. $5.00 / \mathrm{kg}$ jamur merang

Tabel 2. Rekapitulasi Analisis Biaya Jalur Pemasaran Jamur Merang Tankos di Provinsi Lampung

\begin{tabular}{|c|c|c|c|c|c|c|c|c|c|c|}
\hline \multirow{2}{*}{$\begin{array}{l}\mathrm{N} \\
\mathrm{o} .\end{array}$} & \multirow{2}{*}{$\begin{array}{l}\text { Pelaku } \\
\text { Usaha }\end{array}$} & \multicolumn{2}{|l|}{ Modal } & \multirow{2}{*}{$\begin{array}{l}\text { Peneri } \\
\text { maan } \\
\text { Optimis }\end{array}$} & \multicolumn{3}{|c|}{ Pengeluaran } & \multicolumn{3}{|c|}{ Keuntungan Bersih } \\
\hline & & $\begin{array}{l}\text { Minima } \\
1\end{array}$ & $\begin{array}{l}\text { Maksi } \\
\text { mal }\end{array}$ & & Pesimis & $\begin{array}{l}\text { Minima } \\
1\end{array}$ & $\begin{array}{l}\text { Maksim } \\
\text { al }\end{array}$ & Minimal & $\begin{array}{l}\text { Maksima } \\
1\end{array}$ & $\begin{array}{l}\text { Rata- } \\
\text { Rata }\end{array}$ \\
\hline 1. & $\begin{array}{l}\text { Produksi } \\
\text { Jamur }\end{array}$ & $\begin{array}{l}21.863 . \\
444\end{array}$ & $\begin{array}{l}21.863 . \\
444\end{array}$ & $\begin{array}{l}30.800 \\
000\end{array}$ & $\begin{array}{l}28.600 \\
000\end{array}$ & $\begin{array}{l}21.863 . \\
444\end{array}$ & $\begin{array}{l}24.049 . \\
789\end{array}$ & 4.550 .211 & $\begin{array}{l}8.936 .55 \\
6\end{array}$ & $\begin{array}{l}6.743 .38 \\
3\end{array}$ \\
\hline 2. & $\begin{array}{l}\text { Pedagang } \\
\text { Pertama }\end{array}$ & & & & & & & & & \\
\hline & $\begin{array}{l}\text { Luar } \\
\text { Provinsi }\end{array}$ & 26.000 & 28.000 & 40.000 & 40.000 & 8.000 & 12.000 & - & 16.000 & 8.000 \\
\hline & $\begin{array}{l}\text { Dalam } \\
\text { Provinsi }\end{array}$ & 26.000 & 28.000 & 35.000 & 35.000 & 4.000 & 5.000 & 2.000 & 7.500 & 4.750 \\
\hline 3. & $\begin{array}{l}\text { Pedagang } \\
\text { Pengecer }\end{array}$ & & & & & & & & & \\
\hline & $\begin{array}{l}\text { Luar } \\
\text { Provinsi }\end{array}$ & 40.000 & 50.000 & 55.000 & 55.000 & 2.000 & 2.500 & 2.500 & 18.000 & 10.250 \\
\hline & $\begin{array}{l}\text { Dalam } \\
\text { Provinsi }\end{array}$ & 35.000 & 37.500 & 40.000 & 40.000 & 2.000 & 2.500 & - & 10.000 & 5.000 \\
\hline
\end{tabular}

(2) Penjual Pengecer Jamur Merang Tankos.

Penjual pengecer jamur tankos adalah pedagang yang mengambil jamur merang tankos dari penjual pertama untuk dipasarkan ke konsumen. Kegiatan yang dilakukan pedagang pengecer adalah mengemas jamur merang tankos dari dalam keranjang menjadi ukuran 250 gr/kemasan. Kemasan yang digunakan adalah plastik keresek yang akan dijual setiap plastik Rp. 12.500 sampai dengan
15.000 untuk pasar di luar Lampung dan Rp. $\quad 10.000$ sampai dengan 12.500/bungkus (250 gr). Biaya-biaya yang dikeluarkan oleh pedadang pengecer di Provinsi Lampung adalah :

(a) Biaya kemasan plastik dan pengemasan Rp. $1.000 / \mathrm{kg}$

(b) Resiko produk tidak laku = Rp. 1.000 sampai Rp. 1.500/kg jamur merang Hasil analisis keuntungan antar pelaku usaha jamur merang tankos dapat dilihat pada Gambar 2. 


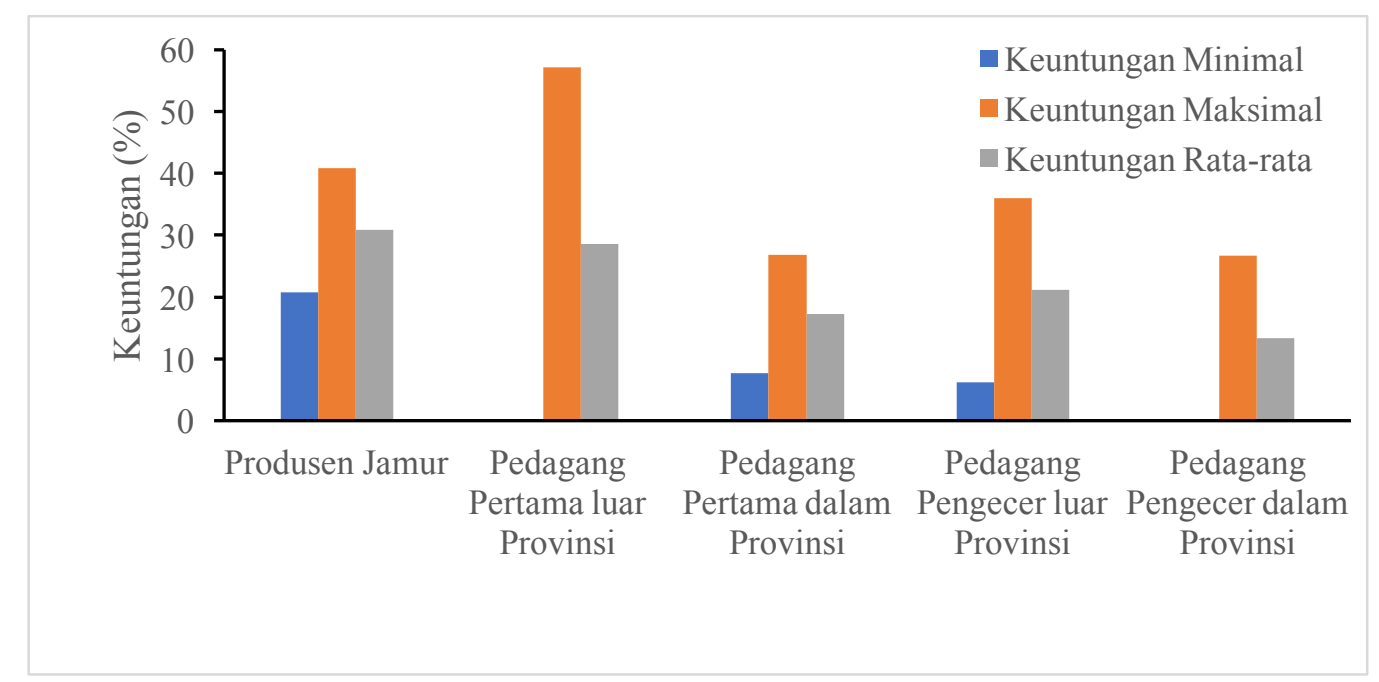

Gambar 2. Hasil Analisis Keuntungan Antar Pelaku Usaha Jamur Merang Tankos

Dari Gambar 2 terlihat bahwa pelaku usaha yang paling tinggi keuntungan rata-ratanya adalah produsen jamur, sedangkan selisih keuntungan maksimal dan minimal tertinggi adalah pedagang pertama antar provinsi, hal ini juga mengindikasikan resiko yang tidak terduga paling tinggi.

\section{(3) Analisis Biaya Produksi Jamur Merang Tankos}

Hasil penelitian menunjukkan biaya yang diperlukan untuk investasi dan operasional usaha jamur merang tankos di Provinsi Lampung dapat dilihat pada Tabel 3 sampai dengan Tabel 7.

Tabel 3. Biaya Investasi Usaha jamur Merang Tankos

\begin{tabular}{|c|c|c|c|c|c|}
\hline No. & Uraian & Jumlah & Satuan & Harga Satuan & Jumlah Biaya \\
\hline 1. & Bambu Tua & 250 & Batang & 14.000 & 3.500 .000 \\
\hline 2. & Asbes Atap & 40 & Lembar & 75.000 & 3.000 .000 \\
\hline 3. & Dinding Plastik/Terpal & 10 & $M^{2}$ & 110.000 & 1.100 .000 \\
\hline 4. & Plastik Putih Tebal & 18 & $\mathrm{Kg}$ & 55.000 & 990.000 \\
\hline 5. & Paku Berbagai Ukuran & 12 & $\mathrm{Kg}$ & 10.000 & 120.000 \\
\hline 6. & Tambang & 4 & Gulung & 150.000 & 600.000 \\
\hline 7. & Selang Air & 20 & M & 4.500 & 90.000 \\
\hline 8. & Sprayer Air & 1 & Unit & 425.000 & 425.000 \\
\hline 9. & Tungku Sterilisasi & 1 & Buah & 550.000 & 550.000 \\
\hline 10. & Kabel Listrik & 20 & M & 3.500 & 70.000 \\
\hline 11. & Balon Lampu $150 \mathrm{~W}$ & 2 & Buah & 120.000 & 240.000 \\
\hline 12. & Scob dan Srcab & 2 & Buah & 40.000 & 80.000 \\
\hline \multirow[t]{4}{*}{13.} & Bak Perendaman & & & & \\
\hline & - Batu Bata & 300 & Buah & 750 & 225.000 \\
\hline & - Semen & 5 & Sak & 60.000 & 300.000 \\
\hline & - Pasir & 3 & $\mathrm{M}^{3}$ & 250.000 & 750.000 \\
\hline \multirow[t]{2}{*}{14.} & Tenaga Kerja & 1 & Orang & 3.000 .000 & 3.000 .000 \\
\hline & Total Biaya & & & & 15.040 .000 \\
\hline
\end{tabular}




\section{ANALISIS JALUR DAN BIAYA PEMASARAN JAMUR MERANG TANKOS DI PROVINSI \\ LAMPUNG}

Sri Astuti dan Sarono

Tabel 4. Biaya Investasi Tambahan/tahun Usaha jamur Merang Tankos

\begin{tabular}{llcccc}
\hline No. & Uraian & Jumlah & Satuan & $\begin{array}{l}\text { Harga } \\
\text { Satuan }\end{array}$ & Jumlah Biaya \\
\hline 1. & Baju Panen & 250 & Pasang & 55.000 & 110.000 \\
2. & Sepatu Boot & 40 & Pasang & 80.000 & 160.000 \\
3. & Sarung Tangan & 10 & Pasang & 20.000 & 240.000 \\
4. & Masker Panen & 18 & Unit & 12.000 & 144.000 \\
5. & Keranjang Panen & 12 & Unit & 40.000 & 200.000 \\
6. & Pisau Panen & 4 & Unit & 25.000 & 50.000 \\
7. & Timbangan & 20 & Unit & 225.000 & 225.000 \\
\hline & Total Biaya & & & $\mathbf{1 . 1 2 9 . 0 0 0}$ \\
\hline
\end{tabular}

Tabel 5. Biaya Operasional untuk Satu Kali Produksi Usaha jamur Merang Tankos

\begin{tabular}{|c|c|c|c|c|c|}
\hline No. & Uraian & Jumlah & Satuan & $\begin{array}{l}\text { Harga } \\
\text { Satuan }\end{array}$ & Jumlah Biaya \\
\hline 1. & TKKS (Cold Diesel) & 1 & Unit & 550.000 & 550.000 \\
\hline 2. & Kapur Dolomit & 25 & $\mathrm{Kg}$ & 1.000 & 25.000 \\
\hline 3. & Bekatul & 50 & $\mathrm{Kg}$ & 2.000 & 100.000 \\
\hline 4. & Kapas & 50 & $\mathrm{Kg}$ & 5.000 & 250.000 \\
\hline 5. & Bibit Jamur & 70 & Bedlock & 10.000 & 700.000 \\
\hline 6. & Kayu Bakar & 2 & $M^{3}$ & 75.000 & 150.000 \\
\hline 7. & Kemasan Plastik & 2 & $\mathrm{Kg}$ & 14.500 & 29.000 \\
\hline 8. & Listrik & 1 & Bulan & 150.000 & 150.000 \\
\hline
\end{tabular}

Tabel 6. Biaya Tenaga Kerja untuk Satu Kali Produksi Usaha jamur Merang Tankos

\begin{tabular}{llccccc}
\hline No. & Uraian & & Jumlah & Satuan & $\begin{array}{c}\text { Harga } \\
\text { Satuan }\end{array}$ & Jumlah Biaya \\
\hline 1. & $\begin{array}{l}\text { Tenaga } \\
\text { Langsung }\end{array}$ & Kerja & 1 & Orang & 2.100 .000 & 2.100 .000 \\
2. & $\begin{array}{l}\text { Tenaga } \\
\text { Borongan }\end{array}$ & Kerja & 1 & Orang & 900.000 & 900.000 \\
\hline & & & & & $\mathbf{3 . 0 0 0 . 0 0 0}$ \\
\hline
\end{tabular}

Tabel 7. Biaya Overhead Pabrik untuk Satu Kali Produksi Usaha jamur Merang Tankos

\begin{tabular}{clccc}
\hline No. & Uraian & Jumlah & Harga Satuan & Jumlah Biaya \\
\hline 1. & Penyusutan Kumbung, dll & 1 & 417.778 & 417.778 \\
2. & Penyusutan alat penunjang & 1 & 94.083 & 94.083 \\
3. & Biaya Operasional Bahan & 1 & 1.954 .0000 & 1.954 .000 \\
4. & $\begin{array}{l}\text { Biaya Tenaga Kerja } \\
\text { Langsung }\end{array}$ & 1 & 3.000 .000 & 3.000 .000 \\
\hline & & & & \\
\hline
\end{tabular}


Dari tabel tersebut terlihat bahwa biaya terbesar usaha jamur merang terletak pada biaya investasi yang mencapai total biaya tetap mencapai Rp. 15.040.000,- Hasil wawancara umur kumbung jamur sekitar 3 sampai 4 tahun atau biaya penyusutan Rp. 417.778/panen.

Biaya tetap untuk usaha jamur merang yang terdiri dari biaya penyusutan kumbung dan biaya penyusutan alat penunjang mencapai Rp. 511.861 atau $9,36 \%$ sedangkan biaya variable mencapai Rp. 4.954 .000 atau 90,64 \%. Menurut Sahadewa dkk. (2019) kecilnya biaya tetap memberikan harapan bagi usaha kecil dan menengah untuk bisa berinvestasi.

Dari tabel-tabel tersebut dapat dihitung total biaya untuk satu siklus produksi dan satu kumbung jamur adalah Rp. 5.465.861. Hasil penelitian menunjukkan bahwa setiap kumbung dan setiap siklus produksi dihasilkan rata-rata $280 \mathrm{~kg}$ jamur merang. Hasil penelitian juga menunjukkan bahwa harga jamur merang tankos antara Rp. 26.000 sampai dengan Rp. 28.000.

Jika harga jual jamur merang tankos Rp. 28.000/kg, maka pendapatan yang diperoleh adalah Rp.7.700.000,atau keuntungannya sebesar Rp. 2.234.139/ siklus tanam/ kumbung. Jika harga jual jamur merang tankos Rp. $26.000 / \mathrm{kg}$, maka pendapatan yang diperoleh adalah Rp.7.150.000,- atau bahwa skala ekonomi seorang untuk usaha jamur merang tankos minimal 4 kumbung. Oleh karena itu, untuk bisa sustainable unit usaha harus memiliki minimal 4 kumbung jamur. Jika unit usaha memiliki 4 kumbung jamur, maka keuntungannya setiap bulan atau satu siklus antara Rp. 550.211 sampai dengan Rp. 8.936.556.

\section{KESIMPULAN}

Jalur pemasaran jamur tankos ada tiga jalur, yaitu jalur panjang (ProdusenPedagang Pertama-Pedagang PengecerKonsumen); jalur sedang (ProdusenPedagang Pengecer-Konsumen); dan jalur pendek (Produsen-Konsumen). Pelaku usaha jamur merang tankos yang paling untung adalah produsen jamur merang tankos, sedangkan yang paling tinggi resiko dan potensi keuntungan tertinggi adalah pedagang pertama luar provinsi.

\section{DAFTAR PUSTAKA}

Amiri M. P. 2010. Project Selection for Oilfields Development by Using the AHP and Fuzzy TOPSIS Methods Expert Systems with Applications 37: 6218-6224.

Anyaoha Kelechi E., Ruben Sakrabani, Kumar Patchigolla, Abdul M. Mouazen. 2018. Review Critical evaluation of oil palm fresh fruit 


\section{ANALISIS JALUR DAN BIAYA PEMASARAN JAMUR MERANG TANKOS DI PROVINSI \\ LAMPUNG}

Sri Astuti dan Sarono

bunch solid wastes as soil

amendments: Prospects and

challenges. Resources,

Conservation and Recycling, 136:

399-409

Bakce D., Syahza A., Bahri S., Irianti M., Riadi RM, dan Asmit B. 2019. Pemanfaatan limbah kelapa sawit untuk budidaya jamur merang dalam upaya perbaikan ekonomi desa: Pengabdian kepada masyarakat di Desa Kampung Baru, Kabupaten Pelalawan. Unri Conference Series: Community Engagement. Volume 1

Burano RS. dan Yuliza F. 2020. Strategi Pemasaran Produk Olahan Jamur Tiram Di Kelompok Wanita Tani Rosella. Menara Ekonomi, VI : 2

Chang, S. H. 2014. An overview of empty fruit bunch from oil palm as feedstock for bio-oil production. Biomass \& Bioenergy, 62: 174181.

David F.R. 2006. Strategic Management: Concepts and Cases. 10th Ed. Alih bahasa : Ichsan Setyo Budi. Penerbit Salemba Empat. Jakarta.

Fitriady MY. 2011. Analisis Peluang Pasar untuk Mengembangkan Produk Olahan Jamur Merang Di Jawa
Timur. Jurnal Ekonomi dan Bisnis, 10: 19-24.

Harun N.H.M., Samad N.A.F., Suriyati S. 2017. Development of kinetics model for torrefaction of empty fruit bunch from palm oil waste. Energy Procedia, 105:744 - 749.

Irjayanti Maya and Anton Mulyono Azis. 2012. Barrier Factors and Potential Solutions for Indonesian SMEs. Procedia Economics and Finance, $4: 3-12$

Kubler Sylvain, J' er'emy Robert, William Derigent, Alexandre Voisin, Yves Le Traon. 2016. A state-of the-art survey \& testbed of Fuzzy AHP (FAHP) applications. Journal of Expert Systems With Applications, 16: 1-33

Li Na, Fengmei Chen, Fengjie Cui, Wenjing Sun, Jinsong Zhang, Lishun Qian, Yan Yang, Di Wu, Ying Dong, Jianxin Jiang, Huaping Yang. 2017. Improved postharvest quality and respiratory activity of straw mushroom (Volvariella volvacea) with ultrasound treatment and controlled relative humidity. Scientia Horticulturae, 225: 56-64

Saelor, S., Kongjan, P. and Sompong, O. T. (2017) 'Thailand Biogas 
Production from Anaerobic Codigestion of Palm Oil Mill Effluent and Empty Fruit Bunches', Energy Procedia, 138, pp. 717-722.

Sahadewa IB, Dewi RK., dan Listia Dewi IA. 2019. Analisis Kelayakan Usahatani Jamur Tiram (pleurotus ostreatus) Kasus: Petani Jamur Tiram di Desa Peguyangan Kaja Kecamatan Denpasar Utara. EJurnal Agribisnis dan Agrowisata, 8: 2

Sarono, Sukaryana Y., Arifin Z., and Sri Astuti. 2020. The analysis of straw mushroom potential development using an empty fruit bunches materials. IOP Conference Series: Materials Science and Engineering, 857 : 012017

Siregar G., Novita D., dan Utami S. 2018. Pemanfaatan Limbah Sawit Sebagai Media Jamur Merang pada Masyarakat Desa Celawan. Jurnal Prodikmas Hasil Pengabdian Masyaraka, II (1):5364.

Sisilia Kristina, Yahya Peranginangin, Retno Setyorini, Nadya Moeliono.
2015. A Framework of Affiliation Partnership between Univesity, SMEs, and Business Sector: A Case Study of PKBL Telkom, Indonesia. Procedia - Social and Behavioral Sciences, 169: 2-12

Tao Hsiao-Hang, Jake L. Snaddon, Eleanor M. Sladea, Ludovic Henneron, Jean-Pierre Calimane, Katherine J. Willisa. 2018. Application of oil palm empty fruit bunch effects on soil biota and functions: A case study in Sumatra, Indonesia. Agriculture, Ecosystems \& Environment, 256: 105-113

Tansakul A. and Lumyong R. 2008. Thermal properties of straw mushroom. Journal of Food Engineering, 87: 91-98

Widiastuti H. and Tri-Panji. 2007. Utilization of spent mushroom (Volvariella volvacea) media derived from empty fruit bunches of oil palm (SMEB) as organic fertilizer on oil palm seedling. Menara Perkebunan, 75 (2): 70-79 